\title{
Dual regulation of mucoidy in Pseudomonas aeruginosa and sigma factor antagonism
}

\author{
J. C. Boucher, M. J. Schurr and V. Deretic ${ }^{\star}$ \\ Department of Microbiology and Immunology, University \\ of Michigan Medical School, 5641 Medical Science \\ Building II, Ann Arbor, Michigan 48109-0620, USA.
}

\section{Summary}

The conversion to mucoid, exopolysaccharide alginate-overproducing phenotype in Pseudomonas aeruginosa during chronic respiratory infections in cystic fibrosis patients occurs via mutations that activate the alternative sigma factor $\operatorname{AlgU}\left(\sigma^{\mathrm{E}}\right)$. In this study, we demonstrate that conversion to mucoidy can be caused via a second, algU-independent pathway, in which alginate production and transcription of the critical $a l g D$ promoter depend on another alternative $\sigma$ factor, $\mathrm{RpoN}\left(\sigma^{54}\right)$. The alg $D$ promoters dependent on $\sigma^{54}$ and $\sigma^{E}$ showed a complete overlap resulting in identical mRNA $5^{\prime}$ ends. The two pathways were not independent, as $\sigma^{54}$ also repressed $\sigma^{\mathrm{E}}$-dependent transcription of algD both in vitro and in vivo. The negative regulatory effect of $\sigma^{54}$ on $\sigma^{E_{-}}$ dependent alg $D$ expression was based on $\sigma^{54}$ binding to the $\operatorname{alg} D$ promoter and its interference with $\sigma^{\mathrm{E}}$ dependent transcription. This phenomenon, referred to here as $\sigma$ factor antagonism, reflects the unique properties of $\sigma^{54}$, which lacks an intrinsic ability to form open transcription initiation complexes. We propose that this peculiar feature of $\sigma^{54}$ has evolved in part to allow its recruitment as a repressor of certain promoter subsets. The repression of $\operatorname{alg} D$ by $\sigma^{54}$ also depends on environmental conditions, supporting the notion that $\sigma$ factor antagonism plays a physiological role in controlling alginate production in $P$. aeruginosa during adaptation to different ecological sites (e.g. biofilm development, stress and other growth conditions) and unique environments in the chronically infected host.

\section{Introduction}

The conversion to exopolysaccharide alginate overproducing, mucoid phenotype provides selective advantage to Pseudomonas aeruginosa in the lungs of cystic fibrosis

Received 10 March, 1999; revised 14 January, 2000; accepted 20 January, 2000. *For correspondence. E-mail Deretic @umich.edu; Tel. (+1) 313763 1580; Fax (+1) 3136476243.
(CF) patients (Welsh et al., 1995; Govan and Deretic, 1996). This phenotypic conversion is caused by mutations that occur in two separate chromosomal loci, termed muc and represented by the prototypical mutations mucA22 and muc23 (Fyfe and Govan, 1980; Martin et al., 1993a,b,c; Govan and Deretic, 1996; Boucher et al., 1997). The majority (84\%) of mucoid $P$. aeruginosa isolates from CF patients carry mutations in the mucA gene resulting in activation of the $\operatorname{alg} D$ promoter, increased alginate production and reduced pulmonary clearance in animal models of respiratory infection (Boucher et al., 1997; Yu et al., 1998). In the absence of muc mutations, activation of the $\operatorname{alg} D$ promoter most likely represents a major decision in the life cycle of $P$. aeruginosa possibly linked to the establishment of biofilms (Davies et al., 1998) or developmental processes such as encystment in a closely related organism Azotobacter vinelandii (Moreno et al., 1998).

In general, alg $D$ expression depends on regulators from the superfamily of bacterial two-component signal transduction systems (Kato and Chakrabarty, 1991; Yu et al., 1997; Selvaraj et al., 1998) and a specialized alternative $\sigma$ factor, $\sigma^{\mathrm{E}}$ (also known as AlgT or AlgU) (Martin et al., 1993a; DeVries and Ohman, 1994), functionally equivalent (Yu et al., 1995) to the extreme heat shock sigma factor $\sigma^{\mathrm{E}}$ (RpoE) found in Escherichia coli and other Gram-negative bacteria ( Rouviére et al., 1995; Missiakas and Raina, 1998). Under conditions of extreme stress, $\sigma^{E}$ is responsible for expression of the genes encoding the heat shock sigma factor $\sigma^{32}(\mathrm{RpoH})$ and additional protective factors, by directing transcription from promoters containing the GAACTT- $\mathrm{N}_{16 / 17}$-TCTGA consensus sequences (Deretic et al., 1994; Missiakas and Raina, 1998). Under normal physiological conditions, $\sigma^{\mathrm{E}}$ is inhibited by its cognate anti- $\sigma$ factor: MucA in $P$. aeruginosa (Xie et al., 1996; Schurr et al., 1996) or RseA in Escherichia coli (Missiakas and Raina, 1998). In a subset of mucoid $P$. aeruginosa isolates from $\mathrm{CF}$ patients, the anti- $\sigma$ factor MucA is inactivated via nonsense and frameshift mutations, resulting in a constitutive production of alginate (Martin et al., 1993c; Boucher et al., 1997). In another set of strains, represented by the mutation muc23, conversion to mucoidy occurs in the absence of mucA alterations. The gene(s) that corresponds to the muc23 mutation and their nature are not known at present.

The transcriptional activation of $\operatorname{alg} D$ and a high-level production of alginate in $P$. aeruginosa also require the 
response regulator AlgB (Selvaraj et al., 1998). Paradoxically, AlgB is homologous to proteins from the NtrC (NRII) subfamily of signal transduction systems that are known to activate transcription specifically in concert with the $\sigma^{54}$-RNA polymerase holoenzyme (Ninfa et al., 1995; Stock et al., 1995). The NtrC-type response regulators are required for the ATP-dependent isomerization of the closed promoter complexes formed by the $\sigma^{54}$-holoenzyme into open transcriptional complexes (Lee et al., 1993; Wang et al., 1995; Perez-Martin and de Lorenzo, 1996; Wang and Gralla, 1996; Syed and Gralla, 1998). Because this specialized function is associated uniquely with $\sigma^{54}$, it seemed unlikely that AlgB could work in concert with $\sigma^{\mathrm{E}}$ (AlgU), a member of the ECF subset of the $\sigma^{70}$ superfamily of $\sigma$ factors (Lonetto et al., 1994) possessing an intrinsic ability to form open promoter complexes (Gralla, 1993; Marr and Roberts, 1997). Interestingly, expression of the mucoid phenotype also depends on a nitrogen source in the growth medium (Deretic et al., 1990). Furthermore, the promoter region of alg $D$ contains a potential sequence matching the consensus for $\sigma^{54}$ promoters (Kimbara and Chakrabarty, 1989; Mohr et al., 1991). Taken together, these considerations suggest that $\sigma^{54}$ could participate in the transcription of $\operatorname{alg} D$ in $P$. aeruginosa. In this study, we show that, in a subset of mucoid $P$. aeruginosa mutants, algD expression and alginate production depend on $\sigma^{54}(\mathrm{RpoN})$ and not on $\sigma^{\mathrm{E}}$ (AlgU), suggesting the existence of two different pathways of conversion to mucoidy. We also demonstrate that these two pathways are not completely independent and that $\sigma^{54}(\mathrm{RpoN})$ acts as a negative regulator when cells overexpress algD via the $\sigma^{\mathrm{E}}(\mathrm{AlgU})$ route.

\section{Results and discussion}

Two alternative pathways lead to increased transcription of algD in mucoid $P$. aeruginosa

Two prototype mucoid strains of $P$. aeruginosa representative of mutations in two key muc loci (Fyfe and Govan, 1980; Martin et al., 1993c; Govan and Deretic, 1996; Boucher et al., 1997) were compared: PAO578Il, carrying
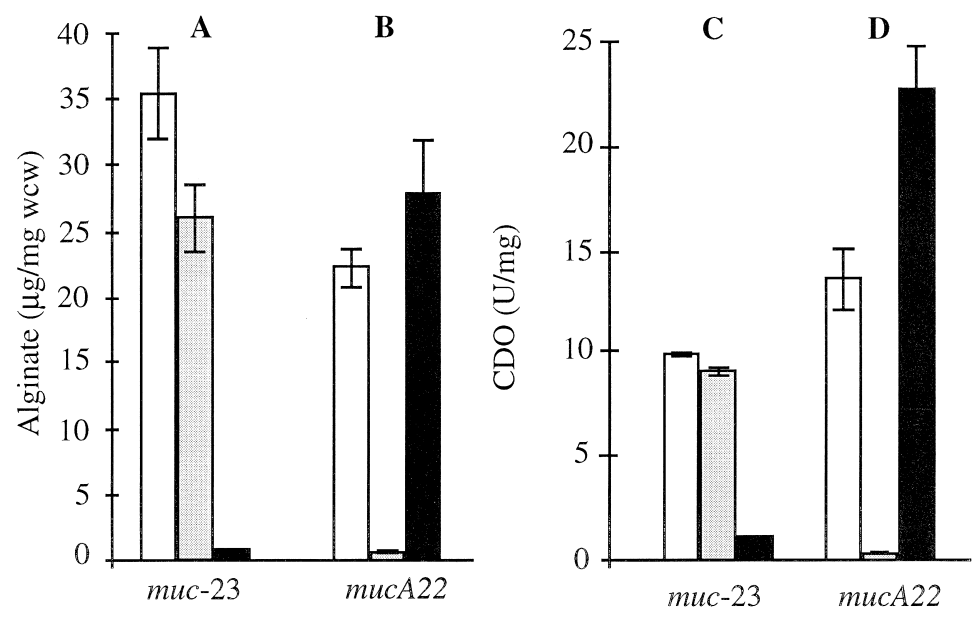

$\operatorname{alg} U^{+} \operatorname{rpoN}^{+} \square \operatorname{alg} U:: \mathrm{Tc}^{\mathrm{r}} \mathrm{rpoN}^{+}$ $\operatorname{alg} U^{+}$rpoN::Tcr
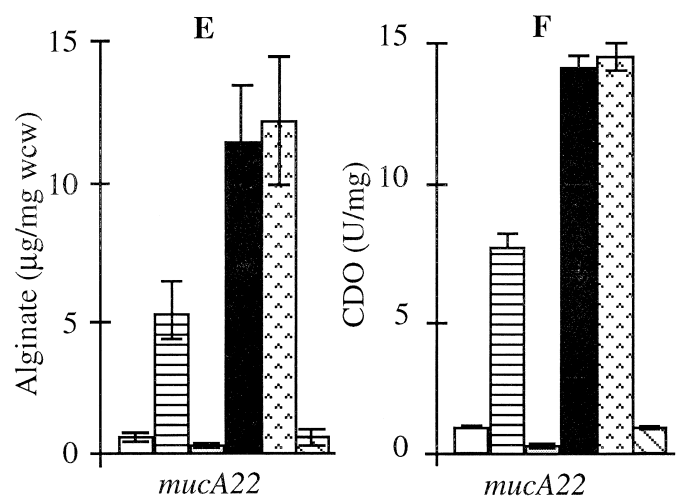

Fig. 1. Two sigma factors, $\sigma^{E}$ and $\sigma^{54}$, can direct $\operatorname{alg} D$ transcription and control mucoid phenotype.

A-D. Different sigma factors, $\sigma^{\mathrm{E}}$ (encoded by alg $U$ ) and $\sigma^{54}$ (encoded by rpoN) are required for alginate production and $\operatorname{alg} D$ transcription in two prototypical muc mutants of $P$. aeruginosa: PAO578II (mucA22) and PAO579 (muc23).

$\mathrm{A}$ and $\mathrm{B}$. Alginate production by $P$. aeruginosa PAO579 (muc23) and PAO578II (mucA22) and their algU:: $\mathrm{Tc}^{r}$ and $r p o N:: \mathrm{Tc}^{r}$ derivatives grown on Pseudomonas Isolation Agar.

$C$ and D. algD-xylE fusion activity (chromosomally encoded) expressed as units of catechol 2,3-deoxygenase (CDO, $x y / E$ gene product) activity $\left(\mathrm{U} \mathrm{mg}^{-1}\right.$ of protein in crude extracts) as previously described (Deretic et al., 1990).

$E$ and $F$. Repression on nitrogen-rich media $\left(\mathrm{NH}_{4}^{+}\right)$in mucA22 cells is dependent on $\sigma^{54}$ (encoded by $r p o N$ ). Strains were grown on minimal media supplemented with $\mathrm{NH}_{4}^{+}$ (nitrogen rich) or $\mathrm{KNO}_{3}$ (nitrogen poor) where indicated. $(\mathrm{p} r p o \mathrm{~N})$, strain harbouring a functional, plasmid-borne $r p o N$ gene. Strains and measurements are the same as in B and D. All values are expressed as mean \pm standard error based on at least three independent experiments. 
the mucA22 mutation within the algU mucABCD locus (Martin et al., 1993c; Boucher et al., 1997), and PAO579, carrying the muc23 mutation (Fyfe and Govan, 1980) that maps in a chromosomal locus different from algU mucABCD in a gene or genes that remain to be characterized. In contrast to mucA mutant $P$. aeruginosa strains, which depend on the alternative sigma factor $\sigma^{\mathrm{E}}$ (AlgU) for alginate production, inactivation of algU affected neither the mucoid phenotype (Fig. 1A) nor algD transcription (Fig. 1C) in the muc23 mucoid strain PA0579. This suggested that $a \lg D$ expression was not dependent on $\sigma^{\mathrm{E}}$ (AlgU) in the muc23 background. As expected, inactivation of alg $U$ (encoding $P$. aeruginosa $\sigma^{\mathrm{E}}$ ) in the mucA22 mutant PAO578II caused a loss of alginate production (Fig. 1B) and algD transcription (Fig. 1D). Alginate production in PAO579 (muc23) still required $\operatorname{alg} D$, as inactivation of this gene completely abrogated alginate production and mucoid phenotype in PAO579 (data not shown). Next, we tested whether an alternative $\sigma$ factor different from $\sigma^{\mathrm{E}}$ (AlgU) was responsible for $a l g D$ expression in PAO579. When $r p o N$ was inactivated in PAO579 (muc23) this strain lost alginate production (Fig. 1A) and algD transcription (Fig. 1C). In contrast, inactivation of $r p o N$ had no immediately apparent effects on the mucA22 strain PAO578II (Fig. 1B and D). These results were consistent with the interpretation that alg $D$ transcription is directed by $\sigma^{\mathrm{E}}$ (AlgU) in the mucA22 background (strain PAO578II) and that it is dependent on $\sigma^{54}$ in the muc23 background (strain PAO579).

To confirm these findings at the mRNA level and to examine the arrangement of the $\sigma^{\mathrm{E}}$ (AlgU) promoter and $\sigma^{54}$-dependent transcript(s) of algD, we next mapped the algD mRNA start sites in the muc23 and mucA22 backgrounds. Suprisingly, the $5^{\prime}$ ends for algD mRNA were identical in muc23 (Fig. 2A, lane 2) and mucA22 cells (Fig. 2B, lane 2). No additional mRNA $5^{\prime}$ ends were detected in the region spanning sequences from -1143 to +432 relative to the $a l g D$ translational start site in either strain. In both cases, the starts matched the previously identified $\sigma^{\mathrm{E}}$ (AlgU) transcriptional start site for algD (Deretic et al., 1987). Inactivation of rpoN in the muc23 background resulted in the loss of transcription from this site (Fig. 2A, lane 3). Inactivation of algU had no effect in the muc23 background (Fig. 2A, lane 4) but, as expected, abrogated transcription in the mucA22 background (Fig. 2B, lane 4). This possibility was consistent with an overlap between the $\sigma^{\mathrm{E}}$ (AlgU) and $\sigma^{54}$ promoter consensus sequences within the algD promoter GGAACTTCCCTCGCAGAGAAAACATCCTA [ $\sigma^{\mathrm{E}}$ consensus (underlined) and $\sigma^{54}$ consensus core bold]. The simplest interpretation of these observations is that $\sigma^{\mathrm{E}}$ (AlgU) and $\sigma^{54}$ (RpoN) can both direct transcription of $a / g D$ from overlapping promoter sequences.

However, an alternative explanation of our data had to
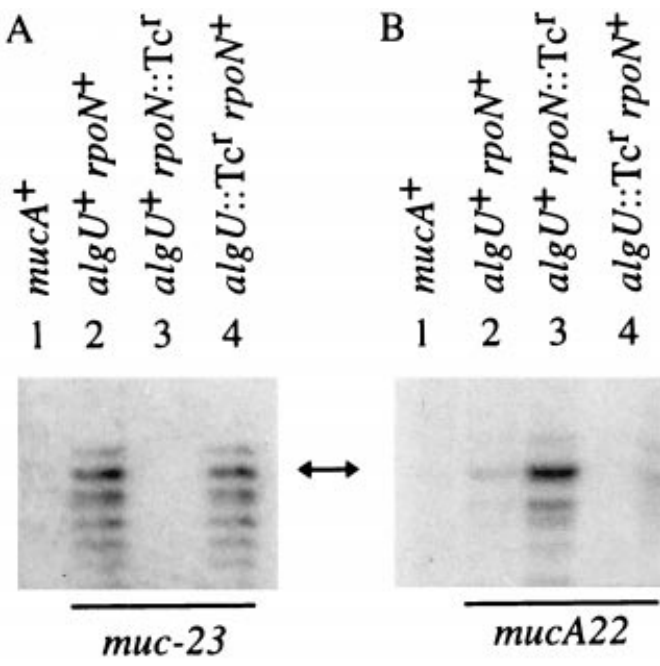

Fig. 2. Coincidence of the $5^{\prime}$ ends of $\sigma^{\mathrm{E}}$ (AlgU)-and $\sigma^{54}$ (RpoN)dependent $a \lg D$ transcripts. Equal amounts of RNA from all strains were used for $\mathrm{S} 1$ nuclease protection analyses carried out as described (see Experimental procedures). Lanes: 1A and 1B, nonmucoid $\left(\right.$ mucA $^{+}$) strain PAO381 parental to both PAO579 (muc23); and PAO578II (mucA22). 2A, PAO579; 2B, PAO578II; 3A and 3B, rpoN::Tc ${ }^{r}$ derivatives of $\mathrm{PAO} 579$ and PAO578II respectively; $4 \mathrm{~A}$ and $4 \mathrm{~B}$, alg U::TC ${ }^{r}$ derivatives of PAO579 and PAO578II respectively. Note, increased alg $D$ transcription in mucA22 alg ${ }^{+} r p o N:: \mathrm{Tc}^{r}$ cells (lane B3) relative to the parental mucA22 $a l g U^{+} r p o N^{+}$strain (lane B2).

be considered. It has been shown that, in the case of a subset of promoters in Bacillus subtilis, two different ECF sigma factors can substitute for each other (Huang et al., 1998), while similar possibilities had been postulated in other instances (Paget et al., 1998). In this alternative scenario, the following three conditions would have to be met to explain our observations: (i) another ECF sigma factor in $P$. aeruginosa had to be able to substitute for $\sigma^{\mathrm{E}}$ (AlgU); (ii) such ECF sigma factor had to be under control by RpoN; and (iii) its expression or activity should be abrogated or reduced in rpoN mutants. We addressed this issue by: (i) examining the recently completed sequence of the $P$. aeruginosa PAO1 genome (www.pseudomonas.com) for genes encoding potential ECF sigma factors; (ii) searching for the presence of a match with the known $\sigma^{54}$ consensus promoter sequences (Ausubel, 1984; Hunt and Magasanik, 1985; Khan et al., 1986) within the region upstream of the putative ECF-encoding open reading frames (ORFs); (iii) examining for the presence of transcripts at the predicted locations; and (iv) determining whether such transcripts were affected by inactivation of rpoN. In addition to the previously characterized ECF sigma factors AlgU, PvdS (Ochsner and Vasil, 1996), PigD (Ochsner and Vasil, 1996), Fiul (Ochsner and Vasil, 1996) and SigX (Duchene et al., 1988), we detected within the complete nucleotide sequence of PAO1 genome a further 15 ORFs encoding potential ECF sigma factors (termed ecfF-ecfT; see Table 1). Of 
Table 1. $P$. aeruginosa ECF $\sigma$ factors and their potential for dependence on $\mathrm{RpoN}$ for transcription.

\begin{tabular}{|c|c|c|c|}
\hline ECF $\sigma^{a, b}$ & $\begin{array}{l}\sigma^{54} \text { promoter } \\
\text { consensus }^{\mathrm{c}}\end{array}$ & Transcript $^{d}$ & $\begin{array}{l}\text { RpoN } \\
\text { dependence }\end{array}$ \\
\hline \multicolumn{4}{|l|}{ Group I } \\
\hline AlgU, PvdS, PigD, Fiul, SigX & - & ND & ND \\
\hline EcfF-H, K-P, R-T & - & ND & ND \\
\hline \multicolumn{4}{|l|}{ Group II } \\
\hline Ecfl & + & - & - \\
\hline EcfJ & + & + & - \\
\hline EcfQ & + & - & - \\
\hline
\end{tabular}

a. ECF $\sigma$ factors included in the analysis were: the previously characterized ECF $\sigma$ factors AlgU (Martin et al., 1993c); PvdS (Ochsner and Vasil, 1996); PigD (Ochsner and Vasil, 1996); Fiul (Ochsner and Vasil, 1996); and SigX (Duchene et al., 1988) and EcfF-T, the putative $P$. aeruginosa ECF $\sigma$ factors encoded by the PAO1 genome (www.pseudomonas.com) identified based on homologies with the known $P$. aeruginosa ECF $\sigma$ factors. EcfF-T were ordered based on percent identity with AlgU as a measure of their probability of substituting for AlgU function. The locations of individual Ecf $\sigma$ factors on the complete $P$. aeruginosa genomic sequence (contig 54, www.pseudomonas.com) and their percent identities with AlgU were; EcfF, 4659367-4659994, 36\%; EcfG, 5086396-5086976, 32\%; EcfH, 4279020-4279628, 29\%; Ecfl, 1903991-1903404, 28\%; EcfJ, 3970477-3969959, 27\%; EcfK, 2846536-2847071, 26\%; EcfL, 6251742-6252284, 26\%; EcfM, 1338419-1337848, 26\%; EcfN, 60333896032880, 26\%; EcfO, 663321-662786, 26\%; EcfP, 5550830-5551348, 24\%; EcfQ, 598403-597795, 23\%; EcfR, 5696756-5697318, 22\%; EcfS, 6093215-6092709, 22\%; and EcfT, 4518571-4519114, 22\% respectively.

b. Group I, no discernible $\sigma^{54}$ promoter consensus. Group II, potential $\sigma^{54}$ promoter consensus sequence present upstream of the coding region. c. The $\sigma^{54}$ promoter consensus sequences used for analysis were: CTGGYAY- $n_{5}-$ TTGCA (Ausubel, 1984); CTGGCAC- $n_{5}-$ TTGCA (Khan and Dixon, 1986); and CTGGYAYR- $n_{4}$-TTGCA (Hunt and Magasanik, 1985). A region consisting of a minimum of 250 bp upstream of the putative ATG of a given Ecf ORF was analysed in each case. -, No discernible $\sigma^{54}$ consensus sequence was observed within the region investigated; + , a potential $\sigma^{54}$ consensus promoter sequence was observed upstream of the putative initiation codon. Potential RpoN promoters were considered based on the following sequences (relative to the ATG codon): ecfl, CCGGCGC- $n_{5}-C C G C A,-242 /-230$; ecfJ, CGGGCCC- $n_{5}-C T G C T$ and CTGGCGT- $n_{5}$-GCGCA, $-201 /-189$ and $-186 /-174$ respectively; ecfQ, CTGGCTC- $n_{5}$-TTGCG, $-69 /-57$.

d. Primer extension analyses were performed using RNA from PAO381 and PAO579 (muc23) as described (see Experimental procedures). -, No transcript of the expected size was detected; +, transcripts of the expected size were detected.

e. Dependence on RpoN was determined by primer extension analysis using RNA from PAO6867 (PAO579 rpoN::Tc') and compared with the signal obtained with RNA from PAO579 $(r p o N)$. - , No change (loss) of transcript was observed in rpoN::Tc ${ }^{r}$ mutant relative to rpoN cells; ND, not determined.

these ORFs, only three had a recognizable potential $\sigma^{54}$ promoter sequence upstream from the coding sequence (Table 1). These genes (ecfl, ecfJ and ecfQ) encoded putative gene products displaying $26 \%-28 \%$ identity to AlgU. Using primer extension analyses and RNA isolated from a panel of $P$. aeruginosa strains, including PAO579 (muc23), a transcript initiating at the predicted position downstream of the putative $\sigma^{54}$ promoter was observed only in the case of ecfl. However, when isogenic rpoN $N^{+}$ and $r p o N:: \mathrm{Tc}^{r}$ strains were compared (Table 1), the observed band was present in both strains (data not shown), suggesting that this ecfl transcript was not rpoN dependent. These experiments suggest that it is unlikely that the $\sigma^{54}$ dependency of $\operatorname{alg} D$ transcription can be explained by a recruitment of an RpoN-dependent ECF $\sigma$ factor to substitute for AlgU in directing transcription of $a \lg D$ in the algU mutant derivative of PAO579. The available data strongly favour the possibility that algD transcription is directed by $\sigma^{\mathrm{E}}$ (AlgU) in mucA mutant mucoid strains and by $\sigma^{54}$ (RpoN) in muc23 mutant mucoid $P$. aeruginosa from promoters with overlapping recognition sequences.

\section{Overlap between $\sigma^{E}$ and $\sigma^{54}$ pathways: nitrogen regulation of algD}

One characteristic of the $P$. aeruginosa mucA22 strain
PAO578II is that it does not produce significant amounts of alginate (i.e. is non-mucoid) on nitrogen-rich minimal media while it is mucoid on minimal media with poor alternative nitrogen sources, such as nitrate (Deretic et al., 1990). The basis for responsiveness of algD expression to a nitrogen source was not previously understood. We wondered whether the involvement of $\sigma^{54}$ (RpoN) uncovered in this study could be related to nitrogen regulation of $\operatorname{alg} D$. Alginate production and $\operatorname{alg} D$ transcription were repressed (Fig. $1 \mathrm{E}$ and $\mathrm{F} ; \mathrm{NH}_{4}^{+}$algU $\mathrm{U}^{+}$ $r p o N^{+}$) when mucA22 cells were grown on ammonia, a nitrogen rich source for $P$. aeruginosa. Alginate production and alg $D$ transcription were activated when cells were grown on nitrate (Fig. $1 \mathrm{E}$ and $\mathrm{F} ; \mathrm{KNO}_{3}^{+}$alg $\mathrm{U}^{+} \mathrm{rpoN}^{+}$), a nitrogen-poor source for $P$. aeruginosa (Deretic et al., 1990), consistent with $a \lg D$ repression in mucA22 cells grown under nitrogen-rich conditions. The activation of the $\operatorname{alg} D$ promoter on nitrate was abolished upon inactivation of algU, suggesting that the transcription of algD under nitrogen-poor conditions was dependent on $\sigma^{\mathrm{E}}$ (AlgU) (Fig. 1F; $\mathrm{KNO}_{3}^{+}$algU:: $\mathrm{Tc}^{r}$ ). This was accompanied by a loss of alginate production (Fig. $1 \mathrm{E} ; \mathrm{KNO}_{3}^{+}$algU:: $\mathrm{Tc}^{r}$ ). Surprisingly, inactivation of $r p o N$ in the mucA22 background caused an increase in alginate production (Fig. 1E; $\mathrm{NH}_{4}^{+}$rpoN::Tc') on nitrogen-rich medium that normally represses mucoidy. This was accompanied by a derepression of algD transcription (Fig. 1F; $\mathrm{NH}_{4}^{+}$ 
rpoN::Tc$\left.{ }^{r}\right)$. Alginate production and algD transcription remained increased upon inactivation of rpoN in cells grown on nitrogen-poor medium (Fig. $1 \mathrm{E}$ and $\mathrm{F} ; \mathrm{KNO}_{3}$ $r p o N:: \mathrm{Tc}^{r}$ ) in keeping with the repressive action of $\sigma^{54}$ (RpoN) and dependence of algD in mucA22 background on $\sigma^{\mathrm{E}}$ (AlgU) for transcription (Fig. $1 \mathrm{E}$ and $\mathrm{F} ; \mathrm{KNO}_{3}$ algU::Tc ${ }^{r}$ ). The RpoN-dependent repression was restored by complementation with the wild-type rpoN gene on a plasmid [Fig. 1E and $\mathrm{F} ; \mathrm{NH}_{4}^{+}$rpoN:: $\mathrm{Tc}^{r}$ (prpoN)]. The derepression of $\operatorname{alg} D$ transcription in $r p o N$ mutant cells was also detectable at the mRNA level as monitored by S1 nuclease protection analysis (Fig. 2). Transcription of algD was increased 4.8-fold in the mucA22 rpoN::Tcr mutant relative to the mucA22 rpoN $\mathrm{N}^{+}$parent (Fig. 2B, lanes 2 and 3). Collectively, the $S 1$ nuclease protection and transcriptional fusion analyses are consistent with the interpretation that RpoN $\left(\sigma^{54}\right)$ or RpoN-dependent processes repress $\sigma^{\mathrm{E}}(\mathrm{AlgU})$-dependent transcription of algD in $P$. aeruginosa under nitrogen-rich conditions. This repression can be lifted by either growth under nitrogen poor conditions or when rpoN is inactivated. Nevertheless, $\sigma^{54}$ was absolutely required as a positive factor for algD expression in muc23 cells in which algD transcription was independent of $\sigma$ (AlgU). These observations suggest a dual role for $\sigma^{54}$ acting both as a positive and as a negative regulator of $\operatorname{alg} D$.

Direct repression by $\sigma^{54}$ of $\sigma$ (AlgU)-dependent algD transcription and $\sigma^{54}$ binding to the algD promoter

While the positive role for $\sigma^{54}$ (RpoN) in algD transcription in muc23 cells is consistent with its direct participation as an alternative sigma subunit of RNA polymerase, its role as a negative regulator could be indirect. To distinguish between direct and indirect effects, we employed the recently established in vitro system for transcription of target promoters by AlgU $\left(\sigma^{\mathrm{E}}\right)$-RNA polymerase holoenzyme (Hershberger et al., 1995; Schurr et al., 1995). Using this assay, we tested whether $\sigma^{54}$ can inhibit $\sigma$ (AlgU)-directed transcription of algD directly. The algD promoter was preincubated with or without purified $\sigma^{54}$, followed by $\sigma^{\mathrm{E}}$ (AlgU)-RNA polymerase addition and resulting transcripts compared (Fig. 3, lanes 1 and 2). Preincubation with $\sigma^{54}$ decreased the amount of the runoff product compared with the sample with no $\sigma^{54}$ in the assay. The inhibitory effect of $\sigma^{54}$ was absent when the experiments were performed with a mutant alg $D$ template $\left(\operatorname{alg} D_{\mathrm{G} \rightarrow \mathrm{T}}\right)$ in which the only non-overlapping residue between the GAACTT $\sigma^{\mathrm{E}}$ consensus sequence and the GG core of the $\sigma^{54}$ promoter consensus sequence was altered (Fig. 3, lanes 3 and 4). Although the $\operatorname{alg} D_{\mathrm{G} \rightarrow \mathrm{T}}$ template displayed a somewhat reduced baseline transcription by the $\mathrm{AlgU}\left(\sigma^{\mathrm{E}}\right)$-holoenzyme (Fig. 3, lane 3), the repression by $\sigma^{54}$ was no longer detectable (Fig. 3, lane 4).

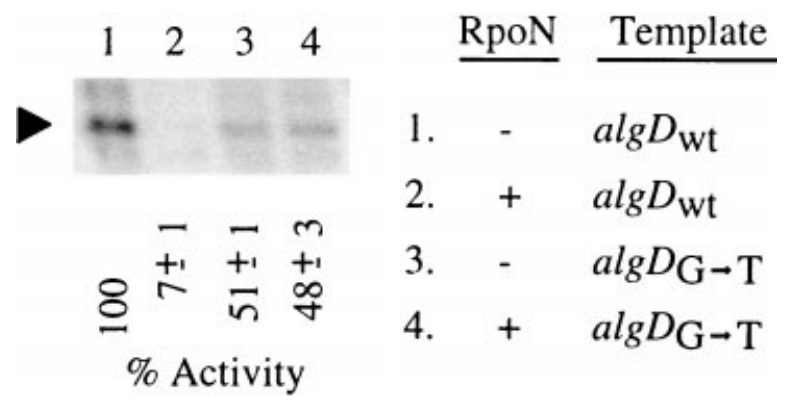

Fig. 3. $\sigma^{54}$ (RpoN) inhibits algD transcription by $\sigma^{\mathrm{E}}$ (AlgU) RNA polymerase. In vitro transcriptional run-off assays with $\sigma^{E}$ (AlgU)-RNA polymerase were carried out as previously described (Schurr et al., 1995; Xie et al., 1996). Templates, alg $D_{\mathrm{wt}}$, wild-type algD promoter; $\operatorname{alg} D_{\mathrm{G} \rightarrow \mathrm{T}}$, its derivative with a destroyed $\sigma^{54}(\mathrm{RpoN})$ consensus but retaining a preserved $\sigma^{\mathrm{E}}$ (AlgU) consensus sequence (see Experimental procedures). Triangle, $\sigma^{\mathrm{E}}$ (AlgU)-dependent algD transcripts obtained with or without preincubation with $\sigma^{54}$ (RpoN; 1.1 pmol) as indicated.\% Activity, phosphorimager quantitation (relative to $a / g D_{\text {wt }}$ transcription as $\left.100 \%\right)$. Values represent means from three independent experiments \pm SE.

The overlap of $P$. aeruginosa $\sigma^{\mathrm{E}}$ (AlgU) and $\sigma^{54}$ promoters in algD suggests the possibility that $\sigma^{54}$ may block access to this site by $\sigma^{\mathrm{E}}$ (AlgU). It has been previously shown that, in contrast to other sigma factors of the $\sigma^{70}$ superfamily, $\sigma^{54}$ can bind to some of its cognate promoters in the absence of core RNA polymerase (Buck and Cannon, 1992). Based on this precedent, we tested whether $\sigma^{54}$ binds to the algD promoter. Addition of $E$. coli $\sigma^{54}$ (E. coli and $P$. aeruginosa $\sigma^{54}$ are functionally interchangeable in the latter organism; Ishimoto and Lory, 1989) to the $\operatorname{alg} D$ promoter probes resulted in the formation of DNA-protein complexes (Fig. 4A). Mutation of a critical G residue (Khan et al., 1986; Wang and Gralla, 1998) within the putative $\sigma^{54}$ consensus sequence of the $\operatorname{alg} D$ promoter $\left(a \lg D_{\mathrm{G} \rightarrow \mathrm{T}}\right)$ abrogated the binding of $\sigma^{54}$ (Fig. 4A, lanes 8-11). As a control, we used AlgR, another regulator previously shown to bind to $\operatorname{alg} D$ and regulate its transcription in concert with $\sigma^{\mathrm{E}}$ (AlgU) (Mohr et al., 1992). No differences in binding of AlgR to $\operatorname{alg} D_{\mathrm{G} \rightarrow \mathrm{T}}$ or to the wild-type algD probe were observed (Fig. 4A, lanes 1 and 2). Binding of $E$. coli $\sigma^{54}$ to the algD promoter was further confirmed by DNase I footprinting. Addition of $\sigma^{54}$ to the algD probe resulted in protection of regions including bases corresponding to the $\sigma^{54}$ promoter consensus GG and GC dinucleotide core (Fig. 4B, lane 1). The position of $\sigma^{54}$ binding relative to the observed RpoN-dependent algD mRNA $5^{\prime}$ end is displaced from the conventional $\sigma^{54}$ promoter $-12 /-24$ configuration, a phenomenon that remains to be explained but could potentially be attributed to in vivo mRNA processing. The gel mobility shift and DNase I footprinting data described above indicate that $\sigma^{54}$ binds to the $\sigma^{54}$-promoter consensus sequence within the $\operatorname{alg} D$ promoter supporting 

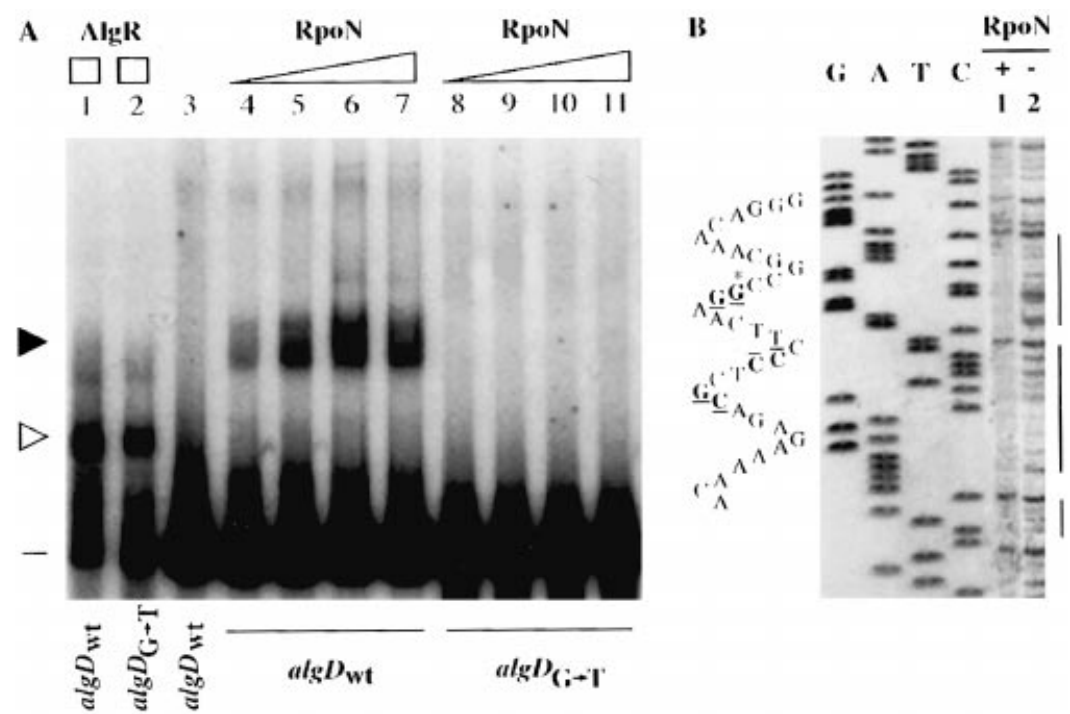

Fig. 4. $\sigma^{54}$ (RpoN) binds to the algD promoter.

A. Gel mobility shift assays were performed as described using $1.9 \mathrm{nmol}$ AlgR [a response regulator previously shown (Mohr et al., 1992) to bind to algD (lanes 1 and 2) or $0.14-0.84 \mathrm{pmol} \sigma^{54}$ (RpoN) (lanes 4-7 and 8-11 containing escalating amounts of $\sigma^{54}: 0.14 \mathrm{pmol}, 0.28 \mathrm{pmol}, 0.56 \mathrm{pmol}$ and $0.84 \mathrm{pmol}$ respectively); AlgR was used here as a control. Boxes, equal amounts of protein; wedges, increasing amounts of protein; filled triangle, $\sigma^{54}$ alg $D$ promoter complex; open triangle, AlgR-alg $D$ promoter complex; bar, unbound $\operatorname{alg} D$ probe; lanes or sets of lanes with $a l g D_{\mathrm{wt}}$ or $a \lg D_{\mathrm{G} \rightarrow \mathrm{T}}$ templates are indicated below the autoradiogram.

B. DNase I footprinting analysis was performed as described in Experimental procedures using the alg $D_{\text {wt }}$ template and 0.84 pmol $\sigma^{54}$. Lanes: 1 $(+)$ RpoN $\left(\sigma^{54}\right)$ added; $2(-)$ no RpoN $\left(\sigma^{54}\right)$; G, A, T, C, sequencing ladder produced using the Palg $D_{\mathrm{R}}$ primer; vertical lines, protected regions. Outlined letters, conserved $\sigma^{54}$ promoter core dinucleotides GG and GC; underscored letters, nucleotides algD matching bases demonstrated to enhance $\sigma^{54}$ binding to a subset of RpoN promoters (Cannon et al., 1993); asterisk, nucleotide changed in $\operatorname{alg} D_{\mathrm{G} \rightarrow \mathrm{T}}($ panel $\mathrm{A})$.

a model of repression by blocking access to the $\sigma^{\mathrm{E}}(\mathrm{AlgU})$ holoenzyme.

Our in vitro experiments suggest a direct repressive effect of $\sigma^{54}$ on $\sigma$-directed transcription but could not exclude the formal possibility that in vivo $\sigma^{54}$ exerted its negative regulatory function differently. For example, $\sigma^{54}$ could act not by directly binding to alg $D$ and repressing $\sigma^{\mathrm{E}}$ (AlgU)-dependent transcription but rather by increasing transcription of another negative regulator (i.e. a repressor) or by competing for the RNA polymerase core with $\sigma^{E}$ (AlgU). Furthermore, absent in our in vitro experiments were putative additional factors potentially present in cells that could keep $\sigma^{54}$ in its active form thus precluding its repressive function in vivo. To discern between the model of direct repression and alternative indirect possibilities, we reasoned that, if $\sigma^{54}$ directly repressed algD in vivo, transcription of the $\operatorname{alg} D_{\mathrm{G} \rightarrow \mathrm{T}}$ variant, no longer capable of binding $\sigma^{54}$, should be derepressed even under nitrogenrich (repressing) conditions while the wild-type promoter should remain repressed. As expected, the levels of algD transcription in mucA22 $r p o N^{+}$cells harbouring the wild-type algD-xylE fusion were low under repressing conditions (Fig. 5A). By comparison, transcription of the $a \lg D_{\mathrm{G} \rightarrow T}-x y \mid E$ fusion was derepressed under identical growth conditions (Fig. 5A). The alg $D_{\mathrm{G} \rightarrow \mathrm{T}}$ promoter was still dependent on $\sigma^{\mathrm{E}}$ (AlgU) for activity, because introduction of a second mutation (palg $D_{\mathrm{G} \rightarrow \mathrm{T} / \mathrm{T} \rightarrow \mathrm{C}}$; destroying the $\sigma^{\mathrm{E}}$ consensus) or inactivation of algU on the chromosome abrogated transcription of the plasmid borne algD (Fig. 5A). A continued $\sigma^{54}$ repression of the wild-type algD promoter on the chromosome in all experiments was evident as illustrated by the fact that cells remained non-mucoid and alginate production was low $\left(0.51 \pm 0.1-0.74 \pm 0.1 \mu \mathrm{g} \mathrm{mg}^{-1}\right.$ wcw). The constructs also behaved as expected in muc23 cells, where the activity of the $a \lg D_{\mathrm{G} \rightarrow T}-x y I E$ fusion was much lower than that of the wild-type $\operatorname{alg} D$, because its transcription was dependent on RpoN $\left(\sigma^{54}\right)$ in these cells (Fig. 5B). Consistent with these and other observations, the $T$ to $C$ mutation $\left(a / g D_{T \rightarrow C}\right)$ within the $-35 \sigma^{\mathrm{E}}(\mathrm{AlgU})$ consensus sequence abrogated transcription of algD in mucA22 but not in the muc23 strain (Fig. 5A and B). These in vivo experiments confirmed the conclusion of our in vitro studies that in alginate-overproducing cells, which acquired mucoidy via the loss of the AlgU-cognate anti$\sigma$ factor MucA, $\sigma^{54}$ (RpoN) played the role of a transcriptional repressor.

Sigma factor antagonism: unique design of $\sigma^{54}$ and repression by a sigma factor

In this study, we have demonstrated that $\sigma^{54}$ can function 


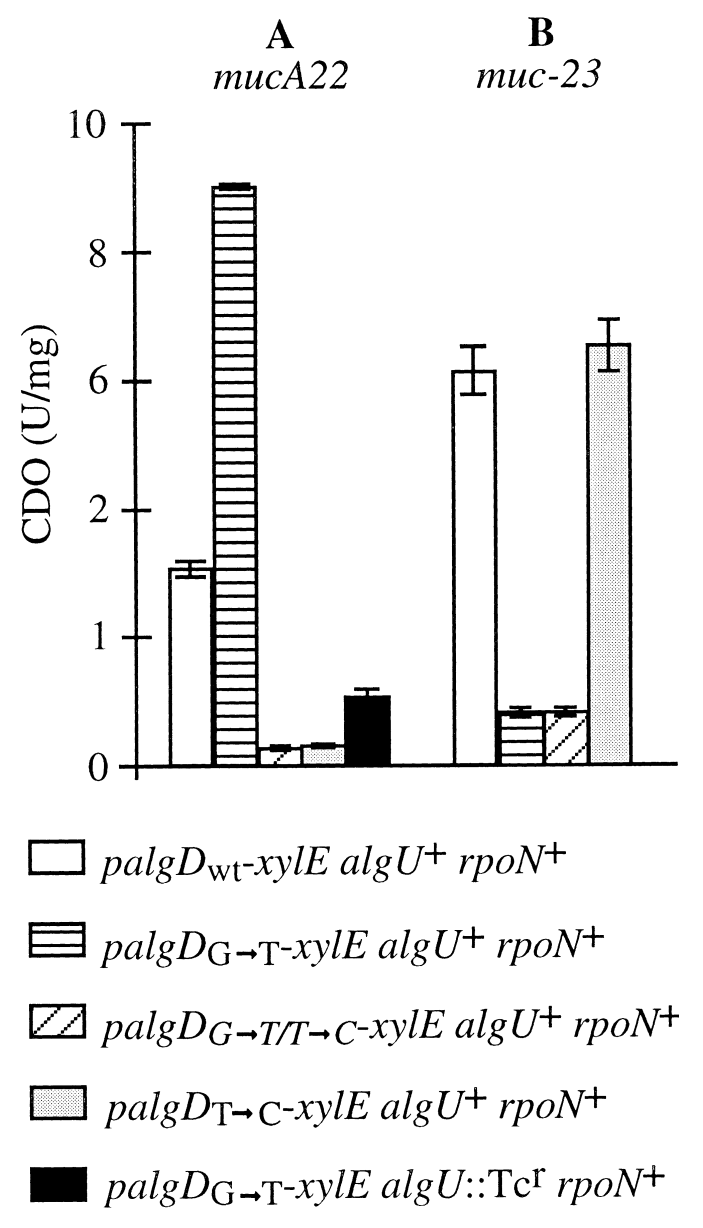

Fig. 5. Elimination of $\mathrm{RpoN}\left(\sigma^{54}\right)$ relieves repression of alg $D$ promoter transcription in vivo. Transcriptional fusion analyses (carried out as in Fig. 1), were performed using strains harbouring the transcriptional fusion constructs: palg $D_{\mathrm{wt}}-x y I E$, palg $D_{\mathrm{G} \rightarrow \mathrm{T}}-x y I E$ (mutation destroying RpoN consensus and eliminating $\sigma^{54}$ binding; see Fig. $3 \mathrm{~B}$ ), palg $D_{\mathrm{T} \rightarrow \mathrm{C}}-x y / E$ [mutation destroying $\sigma^{\mathrm{E}}$ (AlgU) consensus

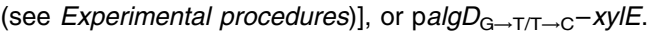

directly as a negative regulator (repressor) of transcription. The finding that $\sigma^{54}$ (or, in vivo, $\sigma^{54}$ RNA polymerase holoenzyme) can bind to a promoter and block transcription initiation by an RNA polymerase holoenzyme containing a different alternative $\sigma$ factor, suggests a novel physiological function for this $\sigma$ subunit of RNA polymerase. RNA polymerase holoenzymes, with the notable exception of $\sigma^{54}$-containing polymerase, form transcription-ready open-promoter complexes (Gralla, 1993; Marr and Roberts, 1997). $\sigma^{54}$ is unique in its absolute requirement for additional transcriptional activators that are needed to isomerize $\sigma^{54}$ polymerasepromoter complexes from a closed to a transcriptioncompetent open state (Lee et al., 1993; Ninfa et al., 1995; Stock et al., 1995; Wang et al., 1995; Perez-Martin and de Lorenzo, 1996; Wang and Gralla, 1996; Syed and Gralla, 1998). It is possible that the unique features of $\sigma^{54}$, which

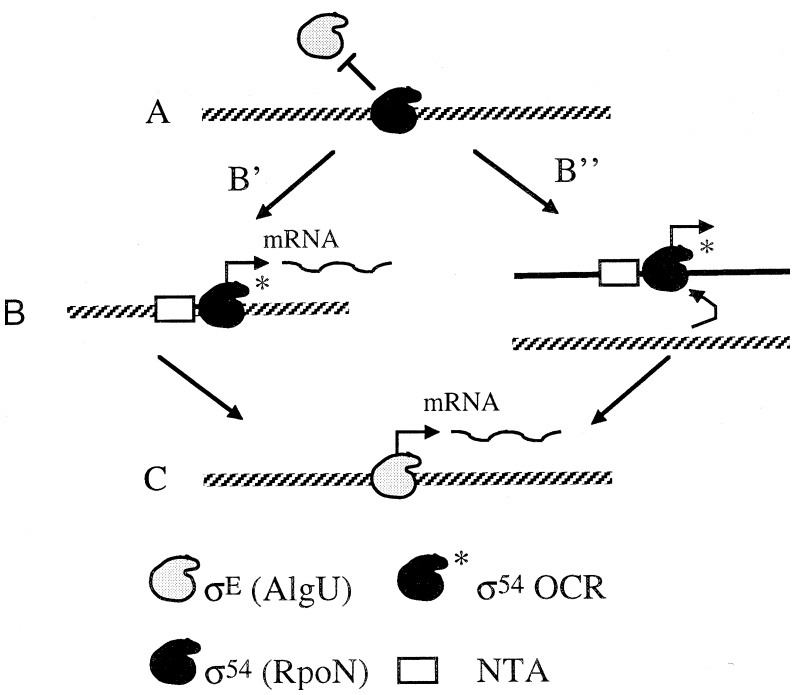

Fig. 6. Model of $\sigma^{54}$ as a repressor: sigma factor antagonism. A. $\sigma^{54}$ bound to the promoter blocks $\sigma^{\mathrm{E}}$-dependent transcription under non-inducing conditions.

B. $\sigma^{54}$ clears the promoter by: (B') directing transcription under inducing conditions promoting formation of OCR (open complexcompetent $\sigma^{54}$-RNA polymerase) in the presence of NTA [NtrC (NRII) type activator] of the same promoter or (B") by being engaged (recruited) in transcription elsewhere on the chromosome.

C. $\sigma^{\mathrm{E}}$ directs transcription by RNA polymerase holoenzyme at a target promoter. For simplicity, other RNA polymerase subunits are not shown.

cannot spontaneously support the isomerization of target promoters from closed to open complexes, increase its repertoire as a regulator of transcription to include a role functionally equivalent to that of a repressor.

Repression by $\sigma^{54}$ offers versatile combinatorial effects not possible with conventional repressor molecules as depicted in the model shown in Fig. 6. In the case of an overlapping promoter configuration, such as in $\operatorname{alg} D, \sigma^{54}$ leads to repression when there are no external activating inputs (Fig. 6A). When environmental conditions dictate, such inputs can be supplied by a cognate response regulator of the NtrC (NRII) type (Ninfa et al., 1995; Stock et al., 1995). A role for at least one regulator of this type, $\mathrm{AlgB}$, has been demonstrated in alginate production and algD transcription (Selvaraj et al., 1998). Thus, AlgB is a likely factor involved in activation of algD via $\sigma^{54}(\mathrm{RpoN})$ and it or another NtrC-type factor could play a role in transducing nitrogen availability signals in algD regulation. When activation of $\sigma^{54}$ takes place (e.g. nitrogen-poor conditions), it can initiate transcription of the subordinate promoter (Fig. 6B') or be engaged elsewhere (Fig. 6B'). Under such conditions, $\sigma^{54}$ clears the site which now can be transcribed by an RNA polymerase holoenzyme containing a different $\sigma$ factor (Fig. 6C). In the case of mucoid mucA mutants, this sigma factor is $\sigma^{\mathrm{E}}$ (AlgU) which is no longer held inactive by the antisigma factor MucA due to mutations such as mucA22. 
In wild-type cells, the relative contributions of either $\sigma$ to the overall transcription levels most likely depend on environmental inputs. While the mutants tested in the present study helped reveal mostly antagonistic relationships between $\sigma^{54}$ and $\sigma^{\mathrm{E}}$, this does not preclude their synergy under certain conditions, with such effects probably masked by the dominant route of transcription in two types of muc mutants investigated. In the absence of inhibitory activity by $\sigma^{54}(\mathrm{RpoN})$, the unbridled $\sigma^{\mathrm{E}}$ (AlgU)-dependent transcription of algD in mucA22 cells is sufficient to render cells mucoid. This does not preclude the possibility of additional transcription by $\sigma^{54}$ holoenzyme under inducing conditions, but this transcription alone is apparently not sufficient to render cells mucoid as inactivation of algU in mucA22 cells results in a severe reduction of $a / g D$ transcription. Conversely, in muc-23 cells, $\sigma^{54}$ (RpoN) dominates algD transcription and $\sigma^{\mathrm{E}}$ (AlgU) appears to play a negligible role as it is inhibited by the antisigma factor MucA. The nature of the genes and mutations in muc-23 cells is not known at present, but it is evident that such mutations activate $\sigma^{54}$ (RpoN)dependent transcription of $a l g D$ to high levels. The muc-23 mutation could be either in a response regulator interacting with $\mathrm{RpoN}$ at $\operatorname{alg} D$ or might activate the system by a novel mechanism.

While the dual (positive and negative) regulatory activity of $\sigma^{54}$ revealed in this study appears to be reserved for overlapping promoters such as in the case of $\operatorname{alg} D$, additional binding site configurations may be possible. It has also been suggested that the pilE promoter of Neisseria gonorrhoeae (Fyfe et al., 1995), which contains overlapping $\sigma^{54}$ consensus and $\sigma^{70}$ consensus sequences, may be under negative regulation by $\sigma^{54}$ albeit this phenomenon was observed only in a heterologous host. A potentially similar effect has been noted during mutational analysis of the $\sigma^{70}$-dependent promoter of the E. coli glnA gene (Reitzer et al., 1987). Additional variations on this theme involving $\sigma^{54}$ and its interacting factors may exist in other systems (Bertoni et al., 1998; Farewell et al., 1998; Marques et al., 1998). However, the exact design involving superimposed $\sigma^{54}$ and $\sigma^{E}$ promoters uncovered here may be reserved only for a narrow subset of critical promoters directing major physiological decisions in Gram-negative organisms. In the case of the system described here, phenomena such as biofilm formation (Davies et al., 1998), developmental processes potentially similar to encystment (Moreno et al., 1998) and prolonged survival under harsh environmental conditions and persistence during chronic infection (Govan and Deretic, 1996; Welsh et al., 1995) may be subject to $\sigma$ factor antagonism as a versatile mechanism providing instant coordination of major physiological systems in the cell. This system also has a built-in circuit breaker that can abort commitment for a major change in the morphological and physiological state of the bacterium.

\section{Experimental procedures}

\section{Strains and constructs}

Pseudomonas aeruginosa PAO381 and the its mucoid derivatives PAO578II and PAO579 have been previously described (Fyfe and Govan, 1980). The plasmids pDMU100 (Martin et al., 1993c) and pKI11 (Ishimoto and Lory, 1989) were used to inactivate $a l g U$ and $r p o N$ via triparental matings (Martin et al., 1993c). The plasmid prpoN (pPT212) (Totten et al., 1990) was used for complementation of rpoN::Tc ${ }^{r}$ mutants. The plasmid pHYDX was used to place the algD::xylE fusion on the $P$. aeruginosa chromosome (Yu et al., 1995). The plasmids pVDX18 and palg $D_{\text {wt }}$ (pVD533) have been previously described (Deretic et al., 1990). A $918 \mathrm{bp}$ PCR product from $P$. aeruginosa PAO1 was the source of the wild-type $\operatorname{alg} D$ promoter. The $\operatorname{alg} D$ promoter containing fragment was cloned into the invitrogen pCR2.1 vector generating $\mathrm{PCBD}-3$ and $a / g D$ sequence verified. The plasmids palg $D_{\mathrm{G} \rightarrow \mathrm{T}}-x y l E$, palg $D_{\mathrm{T} \rightarrow \mathrm{C}}-x y I E$ and palg $D_{\mathrm{G} \rightarrow \mathrm{T} /}$ $\mathrm{C} \rightarrow \mathrm{T}-x y / E$ contained the algD promoter sequence (APS; GGAACTTCCCTCGCAGAGAAAACATCCTA) with the following changes generated by cross-over PCR using the appropriate oligonucleotides: $\mathrm{G} \rightarrow \mathrm{T}$ (APS, bold $\mathrm{G}$ ), $\mathrm{TT} \rightarrow \mathrm{CC}$ (APS, bold TT), and a combination of both $\mathrm{G} \rightarrow \mathrm{T}$ and $\mathrm{T} \rightarrow \mathrm{C}$ changes. For transcriptional fusion analyses, the $\operatorname{alg} D$ promoter variants were fused with the $x y I E$ reporter gene as HindlII-EcoRl fragments cloned into pVDX18. To generate the single stranded algD probe for S1 nuclease assays, the $\operatorname{alg} D$ promoter region was subcloned as a HindIII-Xbal fragment from pCBD-3 into M13 mp19 and the uniformly labelled single-stranded probe generated using the oligonucleotide Palg $D_{\mathrm{R}}\left(5^{\prime}\right.$-CCGATTATTCGAGACGGTTTC-3') as described by Deretic and Konyecsni (1989).

\section{S1 nuclease protection and primer extension analyses}

For S1 nuclease protection assays, RNA was isolated, hybridized to single-stranded $\operatorname{alg} D$ probes, treated with $\mathrm{S} 1$ nuclease and digestion products analysed as previously described by Deretic and Konyecsni (1989). Primer extension analysis was carried out by end-labelling the primers ECF11 (for ecfl) 5'-CGGCGCCATGGGAATG-3', ECF13 (for ecfJ) 5'-GTGGCGCCATGGGCTT-3' and ECF18 (for ecfQ) 5'ATGGGGGTCGAGTGTA-3' ${ }^{\prime}$ with $15 \mathrm{U}$ T4 polynucleotide kinase (GibcoBRL) in $10 \mathrm{mM}$ DTT, $30 \mu \mathrm{Ci}\left[\gamma^{-}{ }^{32} \mathrm{P}\right]-\mathrm{ATP}, 1 \infty$ polynucleotide kinase buffer supplied with enzyme for $1 \mathrm{~h}$ at $37^{\circ} \mathrm{C}$. Reations were stopped by adding $100 \mathrm{mM}$ EDTA, $50 \mu \mathrm{l} \mathrm{TE}$ and heating to $65^{\circ} \mathrm{C}$ for $10 \mathrm{~min}$. Unincorporated nucleotides were removed by Boehringer Mannheim G-25 Sephadex spin columns. Thirty micrograms of RNA per sample was annealed to primers in hybridization buffer (500 mM KCl, $250 \mathrm{mM}$ Tris- $\mathrm{HCl} \mathrm{pH} \mathrm{8.3)} \mathrm{for} 1 \mathrm{~min}$ at $95^{\circ} \mathrm{C}$ followed by $2 \mathrm{~min}$ at $55^{\circ} \mathrm{C}$ and $15 \mathrm{~min}$ on ice. Extensions were carried out in $10 \mathrm{mM}$ DTT, $250 \mu \mathrm{M}$ dNTP's, GibcoBRL Superscript II RT (GibcoBRL) and reverse transcriptase buffer supplied with enzyme at $44^{\circ} \mathrm{C}$ for $45 \mathrm{~min}$. Reactions 
were stopped, boiled and analysed on a polyacrylamide sequencing gel along the side of the sequencing ladder generated using the same primer and corresponding PCR fragment as the template.

\section{In vitro transcriptional run-off analysis}

For in vitro transcriptional run-off analyses, a $142 \mathrm{bp}$ fragment containing wild-type $\operatorname{alg} D$ and $a \lg D_{\mathrm{G} \rightarrow \mathrm{T}}$ were generated by PCR using the oligonucleotides $5^{\prime}$-TCCAAATATTTCGCGAGCGGGACGAACGGTCG-3' 5'-GTTTGTCCCTCGGAGCGGAA-3' and pCBD-3 and palg $D_{\mathrm{G} \rightarrow \mathrm{T}}$ as templates respectively. For inhibition studies, $E$. coli $\sigma^{54}$ (1.1 pmol) was preincubated at room temperature with the algD promoter template for $10 \mathrm{~min}$ in $10 \mathrm{mM}$ Tris- $\mathrm{HCl} \mathrm{pH} \mathrm{7.5,}$ $30 \mathrm{mM} \mathrm{KCl}, 10 \mathrm{mM} \mathrm{MgCl} 2$ and $1 \mathrm{mM}$ DTT. AlgU and RNA polymerase were incubated together on ice for $10 \mathrm{~min}$ in $10 \mathrm{mM}$ Tris- $\mathrm{HCl} \mathrm{pH} 8.0,10 \mathrm{mM} \mathrm{KCl}, 10 \mathrm{mM} \beta$-mercaptoethanol, $1 \mathrm{mM}$ EDTA, $0.4 \mathrm{mg} \mathrm{ml}^{-1} \mathrm{BSA}$ and $0.1 \%$ Triton $\mathrm{X}$ 100 to allow association. AlgU and RNA polymerase was added to each reaction, incubated for $10 \mathrm{~min}$ at room temperature, $0.2 \mathrm{mM}$ ATP, GTP, CTP and $3 \mu \mathrm{Ci}\left[\alpha^{-32} \mathrm{P}\right]-$ UTP was then added and further incubated for $15 \mathrm{~min}$ and reaction stopped by adding $150 \mathrm{mM}$ sodium acetate and ethanol. Precipitated DNA was dissolved and analysed on a polyacrylamide sequencing gel.

\section{Mobility shift DNA-binding assay}

Probes were generated by PCR using the oligonucleotides 5'-GGCCATCAAGTTGGTATCAA-3' ${ }^{\prime}$ and Palg $D_{\mathrm{R}}$ as primers and pCBD-3 and palg $D_{\mathrm{G} \rightarrow \mathrm{T}}$, as templates. End-labelled probes $\left({ }^{32} \mathrm{P}\right)$ were incubated with AlgR $(1.9 \mathrm{nmol})$ or $E$. coli RpoN (0.14-0.83 pmol) in a total volume of $10 \mu$ l containing $25 \mathrm{mM}$ Tris- $\mathrm{HCl} \mathrm{pH} 8.0,6 \mathrm{mM} \mathrm{MgCl}_{2}, 0.5 \mathrm{mM}$ EDTA, $0.5 \mathrm{mM}$ DTT, $20 \mathrm{mM} \mathrm{KCl}, 5 \%$ glycerol, $100 \mu \mathrm{g} \mathrm{ml}^{-1}$ poly(dl-dC), and $100 \mu \mathrm{g} \mathrm{ml}^{-1}$ ssDNA. DNA-protein complexes were separated from the unbound probe on a $5 \%$ native polyacrylamide gel (Mohr et al., 1992) and visualized by autoradiography.

\section{DNase I footprinting analysis}

The primers Palg $D_{\mathrm{R}}$ and ADL2 (5'-GGCCATCAAGTTCCTATCAA-3 ${ }^{\prime}$ ) were used to generate a $160 \mathrm{bp}$ probe. The probe was end-labelled using $3 \mu \mathrm{l}$ of PCR product, $2 \mu \mathrm{l}$ of polynucleotide kinase buffer (Boehringer Mannheim), $3 \mu \mathrm{l}$ of $\left[{ }^{32} \mathrm{P}\right]-\mathrm{ATP}$, and $15 \mathrm{U}$ polynucleotide kinase (Boehringer Mannheim), digested with EcoRV and purified. Gel mobility shift $\sigma^{54}$-DNA binding reaction mixtures were incubated for $10 \mathrm{~min}$ at room temperature, $\mathrm{MgCl}_{2}$ added (final concentration of $5 \mathrm{mM}$ ) and DNase I digestions carried out on ice for $2 \mathrm{~min}$. Reactions were stopped by addition of $40 \mathrm{mM}$ EDTA and separated on a non-denaturing polyacrylamide gel as described for gel mobility shifts. Bands corresponding to protein bound and unbound DNA were excised from the gel and eluted in $500 \mathrm{mM} \mathrm{NH}_{4} \mathrm{OAc}, 1 \%$ SDS and $1 \mathrm{mM}$ EDTA. Eluates were phenol extracted and DNA precipitated in $550 \mu \mathrm{l}$ of $\mathrm{EtOH}, 1 \mu \mathrm{g}$ of tRNA and $10 \mu \mathrm{g}$ of glycogen. DNA was resuspended in $10 \mu \mathrm{l}$ of formamide buffer and run alongside a sequencing ladder generated using the $P a l g D_{R}$ primer on an $8 \%$ polyacrylamide sequencing gel.

\section{Alginate assay}

Alginate was determined by the method of Knutson and Jeanes (1976). The amount of alginate was expressed in $\mu \mathrm{g}$ of uronic acid per $\mathrm{mg}$ of wet-cell weight.

\section{Acknowledgements}

We thank A. Ninfa and D. Rowen for gifts of purified E. coli $\sigma^{54}$ (RpoN). This work was supported by grants Al31139 from NIH and 96PO from Cystic Fibrosis Foundation.

\section{References}

Ausubel, F.M. (1984) Regulation of nitrogen fixation genes. Cell 37: 5-6.

Bertoni, G., de Marques, S., and Lorenzo, V. (1998) Activation of the toluene-responsive regulator XyIR causes a transcriptional switch between sigma54 and sigma70 promoters at the divergent $\mathrm{Pr} / \mathrm{Ps}$ region of the TOL plasmid. Mol Microbiol 27: 651-659.

Boucher, J.C., Yu, H., Mudd, M.H., and Deretic, V. (1997) Mucoid Pseudomonas aeruginosa in cystic fibrosis: characterization of muc mutations in clinical isolates and analysis of clearance in a mouse model of respiratory infection. Infect Immun 65: 38383846.

Buck, M., and Cannon, W. (1992) Specific binding of the transcription factor sigma-54 to promoter DNA. Nature 358: 422-424.

Cannon, W., Claverie-Martin, F., Austin, S., and Buck, M. (1993) Core RNA polymerase assists binding of the transcription factor $\sigma^{54}$ to promoter DNA. Mol Microbiol 8: 287-298.

Davies, D.G., Parsek, M.R., Pearson, J.P., Iglewski, B.H., Costerton, J.W., and Greenberg, E.P. (1998) The involvement of cell-to-cell signals in the development of a bacterial biofilm. Science 280: 295-298.

Deretic, V., Gill, J.F., and Chakrabarty, A.M. (1987) Pseudomonas aeruginosa infection in cystic fibrosis: nucleotide sequence and transcriptional regulation of the algD gene. Nucleic Acids Res 15: 4567-4581.

Deretic, V., Govan, J.R., Konyecsni, W.M., and Martin, D.W. (1990) Mucoid Pseudomonas aeruginosa in cystic fibrosis: mutations in the muc loci affect transcription of the algR and $a \lg D$ genes in response to environmental stimuli. Mol Microbiol 4: $189-196$.

Deretic, V., and Konyecsni, W.M. (1989) Control of mucoidy in Pseudomonas aeruginosa: transcription regulation of $a l g R$ and identification of the second regulatory gene, algQ. J Bacteriol 171: 3680-3688.

Deretic, V., Schurr, M.J., Boucher, J.C., and Martin, D.W. (1994) Conversion of Pseudomonas aeruginosa to mucoidy in cystic fibrosis: environmental stress and regulation of bacterial virulence by alternative sigma factors. J Bacteriol 176: 27732780.

DeVries, C.A., and Ohman, D.E. (1994) Mucoid-to-nonmucoid conversion in alginate-producing Pseudomonas aeruginosa often results from spontaneous mutations in alg $T$, encoding a putative alternate sigma factor, and shows evidence for autoregulation. J Bacteriol 176: 6677-6687. 
Duchene, M., Schweizer, A., Lottspeich, F., Krauss, G., Marget, M., Vogel, K., et al. (1988) Sequence and transcriptional start site of the Pseudomonas aeruginosa outer membrane porin protein $\mathrm{F}$ gene. J Bacteriol 170: 155-162.

Farewell, A., Kvint, K., and Nystrom, T. (1998) Negative regulation by RpoS: a case of sigma factor competition. Mol Microbiol 29: 1039-1051.

Fyfe, J.A., Carrick, C.S., and Davies, J.K. (1995). The pilE gene of Neisseria gonorrhoeae MS11 is transcribed from a sigma 70 promoter during growth in vitro. J Bacteriol 177: 3781-3787.

Fyfe, J.A.M., and Govan, J.R.W. (1980) Alginate synthesis in mucoid Pseudomonas aeruginosa: a chromosomal locus involved in control. J Gen Microbiol 119: 443-450.

Govan, J.R.W., and Deretic, V. (1996) Microbial pathogenesis in cystic fibrosis: mucoid Pseudomonas aeruginosa and Burkholderia cepacia. Microbiol Rev 60: 539-574.

Gralla, J.D. (1993) Opening promoters for m-RNA transcription. Cell Mol Biol Res 39: 319-322.

Hershberger, C.D., Ye, R.W., Parsek, M.R., Xie, Z.-D., and Chakrabarty, A.M. (1995) The algT (algU) gene of Pseudomonas aeruginosa, a key regulator involved in alginate biosynthesis, encodes an alternative $\sigma$ factor $\left(\sigma^{\mathrm{E}}\right)$. Proc Natl Acad Sci USA 92: 7941-7945.

Huang, X., Fredrick, K.L., and Helmann, J.D. (1998) Promoter recognition by Bacillus subtilis $\sigma^{\mathrm{W}}$ : autoregulation and partial overlap with the $\sigma^{\mathrm{X}}$ regulon. J Bacteriol 180: 3765-3770.

Hunt, T.P., and Magasanik, B. (1985) Transcription of $g \ln A$ by purified Escherichia coli components: Core RNA polymerase and the products of $g I n F, g I n G$, and $g I n L$. Proc Natl Acad Sci USA 82: 8453-8457.

Ishimoto, K.S., and Lory, S. (1989) Formation of pilin in Pseudomonas aeruginosa requires the alternative sigma factor (RpoN) of RNA polymerase. Proc Natl Acad Sci USA 86: 1954-1957.

Kato, J., and Chakrabarty, A.M. (1991) Purification of the regulatory protein AlgR1 and its binding in the far upstream region of the algD promoter in Pseudomonas aeruginosa. Proc Natl Acad Sci USA 88: 1760-1764.

Khan, H., Buck, M., and Dixon, R. (1986) Deletion loop mutagenesis of the nifL promoter from Klebsiella pneumoniae: role of the -26 to -12 region in promoter function. Gene 45 : 281-288.

Kimbara, K., and Chakrabarty, A.M. (1989) Control of alginate synthesis in Pseudomonas aeruginosa: regulation of the algR1 gene. Biochem Biophys Res Com 164: 601-608.

Knutson, C.A., and Jeanes, A. (1976) A new modification of the carbazole reaction: application to heteropolysaccharides. Anal Biochem 24: 470-481.

Lee, H.S., Berger, D.K., and Kustu, S. (1993) Activity of purified NIFA, a transcriptional activator of nitrogen fixation genes. Proc Natl Acad Sci USA 90: 2266-2270.

Lonetto, M.A., Brown, K.L., Rudd, K.E., and Buttner, M.J. (1994) Analysis of the Streptomyces coelicolor sigE gene reveals the existence of a subfamily of eubacterial RNA polymerase $\sigma$ factors involved in the regulation of extracytoplasmic functions. Proc Natl Acad Sci USA 86: 7573-7577.

Marques, S., Gallegos, M.T., Manzanera, M., Holtel, A., Timmis, K.N., and Ramos, J.L. (1998) Activation and repression of transcription at the double tandem divergent promoters for the $x y I R$ and $x y / S$ genes of the TOL plasmid of Pseudomonas putida. J Bacteriol 180: 2889-2894.

Marr, M.T., and Roberts, J.W. (1997) Promoter recognition as measured by binding of polymerase to nontemplate strand oligonucleotide. Science 276: 1258-1260.
Martin, D.W., Holloway, B.W., and Deretic, V. (1993a) Characterization of a locus determining the mucoid status of Pseudomonas aeruginosa: algU shows sequence similarities with a Bacillus sigma factor. J Bacteriol 175: 1153-1164.

Martin, D.W., Schurr, M.J., Mudd, M.H., and Deretic, V. (1993b) Differentiation of Pseudomonas aeruginosa into the alginateproducing form: inactivation of $m u c B$ causes conversion to mucoidy. Mol Microbiol 9: 497-506.

Martin, D.W., Schurr, M.J., Mudd, M.H., Govan, J.R.W., Holloway, B.W., and Deretic, V. (1993c) Mechanism of conversion to mucoidy in Pseudomonas aeruginosa infecting cystic fibrosis patients. Proc Natl Acad Sci USA 90: 8377-8381.

Missiakas, D., and Raina, S. (1998) The extracytoplasmic function sigma factors: role and regulation. Mol Microbiol 28: 1059-1066.

Mohr, C.D., Hibler, N.S., and Deretic, V. (1991) AlgR, a response regulator controlling mucoidy in Pseudomonas aeruginosa, binds to the FUS sites of the algD promoter located unusually far upstream from the mRNA start site. J Bacteriol 173: 51365143.

Mohr, C.D., Leveau, J.H.J., Krieg, D.P., Hibler, N.S., and Deretic, V. (1992) AlgR-binding sites within the algD promoter make up a set of inverted repeates separated by a large intervening segment of DNA. J Bacteriol 174: 6624-6633.

Moreno, S., Najera, R., Guzman, J., Soberon-Chavez, G., and Espin, G. (1998) Role of alternative sigma factor algU in encystment of Azotobacter vinelandii. J Bacteriol 180: 27662769.

Ninfa, A.J., Atkinson, M.R., Kamberov, E.S., Feng, J., and Ninfa, E.G. (1995) Control of nitrogen assimilation by the NRI-NRII two-component system of enteric bacteria. In Two Component Signal Transduction. Hoch, J.A., and Silhavy, T.J. (eds). Washington: American Society for Microbiology Press, pp. 67-88.

Ochsner, U.A., and Vasil, M.L. (1996) Gene repression by the ferric uptake regulator in Pseudomonas aeruginosa: Cycle selection of iron-regulated genes. Proc Natl Acad Sci USA 93: 4409-4414.

Paget, M.S.B., Kang, J.-H.R., and Buttner, M.J. (1998) $\sigma^{R}$, an RNA polymerase sigma factor that modulates expression of the thioredoxin system in response to oxidative stress in Streptomyces coelicolor A3(2). EMBO J 17: 5776-5782.

Perez-Martin, J., and de Lorenzo, V. (1996) ATP binding to the sigma 54-dependent activator XyIR triggers a protein multimerization cycle catalyzed by UAS DNA. Cell 86: 331339.

Reitzer, L.J., Bueno, R., Cheng, W.D., Abrams, S.A., Rothstein, D.M., Hunt, T.P., et al. (1987) Mutations that create new promoters suppress the sigma 54 dependence of gInA transcription in Escherichia coli. J Bacteriol 169: 42794284.

Rouviére, P.E., De Las Penas, A., Mecsas, J., Lu, C.Z., Rudd, K.E., and Gross, C.A. (1995) rpoE, the gene encoding the second heat-shock sigma factor, $\sigma^{\mathrm{E}}$, in Escherichia coli. EMBO J 14: 1032-1042.

Schurr, M.J., Yu, H., Martinez-Salazar, J.M., Boucher, J.C., and Deretic, V. (1996) Control of AlgU, member of the $\sigma^{\mathrm{E}}$-like family of stress sigma factors, by the negative regulators MucA and MucB and Pseudomonas aeruginosa conversion to mucoidy in cystic fibrosis. J Bacteriol 178: 4997-5004.

Schurr, M.J., Yu, H., Martinez-Salazar, J.M., Hibler, N.S., and Deretic, V. (1995) Biochemical characterization and posttranslational modification of AlgU, a regulator of stress response in 
Pseudomonas aeruginosa. Biochem Biophys Res Comm 216: 874-880.

Selvaraj, M.S., Ohman, D.E., Quarless, R., Hassett, D.J., and Wozniak, D.J. (1998) Phosphorylation-independent activity of the response regulators $\mathrm{AlgB}$ and $\mathrm{AlgR}$ in promoting alginate biosynthesis in mucoid Pseudomonas aeruginosa. $J$ Bacteriol 180: 956-968.

Stock, J.B., Surette, M.G., Levit, M., and Park, P. (1995) Twocomponent signal transduction systems: structure-function relationships and mechanisms of catalysis. In Two-Component Signal Transduction. Hoch, J.A., and Silhavy, T.J. (eds). Washington: American Society for Microbiology Press, pp. 25-52.

Syed, A., and Gralla, J.D. (1998) Identification of an N-terminal region of sigma 54 required for enhancer responsiveness. $J$ Bacteriol 180: 5619-5625.

Totten, P.A., Lara, J.C., and Lory, S. (1990) The rpoN gene product of $P$ seudomonas aeruginosa is required for expression of diverse genes, including the flagellin gene. J Bacteriol 172: 389-396.

Wang, J.T., and Gralla, J.D. (1996) The transcription initiation pathway of sigma 54 mutants that bypass the enhancer protein requirement. Implications for the mechanism of activation. $J$ Biol Chem 271: 32707-32713.

Wang, L., and Gralla, J.D. (1998) Multiple in vivo roles for the -12-region elements of sigma 54 promoters. J Bacteriol 180: 5626-5631.
Wang, J.T., Syed, A., Hsieh, M., and Gralla, J.D. (1995) Converting Escherichia coli RNA polymerase into an enhancer-responsive enzyme: role of an $\mathrm{NH} 2$-terminal leucine patch in sigma 54. Science 270: 992-994.

Welsh, M.J., Tsui, L.-C., Boat, T.F., and Beaudet, A.L. (1995) The metabolic and molecular basis of inherited disease. In Cystic Fibrosis. Beaudet, A.L., Sly, W.S., and Valle, D. (eds). New York: McGraw-Hill, Inc., pp. 3799-3876.

Xie, Z.D., Hershberger, C.D., Shankar, S., Ye, R.W., and Chakrabarty, A.M. (1996) Sigma factor-anti-sigma factor interaction in alginate synthesis: inhibition of AlgT by MucA. $J$ Bacteriol 178: 4990-4996.

Yu, H., Hanes, M., Chrisp, C.E., Boucher, J.C., and Deretic, V. (1998) Microbial pathogenesis in cystic fibrosis: pulmonary clearance of mucoid Pseudomonas aeruginosa and inflammation in a mouse model of repeated respiratory challenge. Infect Immun 66: 280-288.

Yu, H., Mudd, M., Boucher, J.C., Schurr, M.J., and Deretic V. (1997) Identification of the algZ gene upstream of the response regulatory $a l g R$ and its participation in control of alginate production in Pseudomonas aeruginosa. J Bacteriol 179: 187193.

Yu, H., Schurr, M.J., and Deretic, V. (1995) Functional equivalence of Escherichia coli $\sigma^{\mathrm{E}}$ and Pseudomonas aeruginosa AlgU: $E$. coli rpoE restores mucoidy and reduces sensitivity to reactive oxygen intermediates in algU mutants of $P$. aeruginosa. J Bacteriol 177: 3259-3268. 